REVISTA DE DERECHO UNED, NÚM. 27, 2021

\title{
DIPLOMACIA DEPORTIVA, UNA DISCIPLINA POR DESARROLLAR.
}

\author{
SPORTS DIPLOMACY. A DISCIPLINE TO DEVELOP.
}

JAVIER SOBRINO DE TORO

Profesor de Estrategia Empresarial de la Universidad Pontificia de Comillas y de ICADE Business School.

Director del módulo de gestión de eventos deportivos del Curso Superior en Gestión Deportiva de CIES y la Real Federación Española de Fútbol.

Programa de Doctorado en Derecho y Ciencias Sociales (UNED)

Sumario: I. Introducción. II. La importancia de la diplomacia deportiva. III. Los objetivos de la diplomacia deportiva. A. Objetivos de identificación. 1. Fomento de sentimiento identitario propio. 2. Posicionamiento internacional. B. Objetivos de intercambio. 1. Comunicación internacional. 2. Gestión de las relaciones entre países. 3. Contribución económica. C. Objetivos de contribución. 1. Desarrollo social de terceros países. 2. Cooperación. IV. Los medios de la diplomacia deportiva. A. Los agentes deportivos. B. Las actividades deportivas. C. Infraestructuras, instalaciones y localizaciones deportivas. D. Gestión del conocimiento, mejores prácticas y desarrollo tecnológico. E. Productos y servicios relacionados con el sector. $V$. Riesgos de la diplomacia deportiva. VI. Conclusión: el momento para desarrollar la diplomacia deportiva.

Resumen: El deporte es el fenómeno social más importante de los últimos años con una proyección multinacional inigualable. Como tal puede ser utilizado como instrumento de la acción exterior por parte de los países y de las empresas a través de la denominada diplomacia deportiva. 
El presente artículo aborda esta disciplina desde el punto de vista de los objetivos a los que puede contribuir y de los medios de los que puede disponer. Los objetivos son muy variados, estructurándose en objetivos de identificación, intercambio y contribución. Por lo que respecta a los medios, estos incluyen agentes deportivos, actividades, infraestructuras, conocimiento y productos y servicios.

La adecuada definición y gestión de dichos objetivos y medios supone un gran potencial en el empeño de estructurar, desarrollar y, sobre todo, aplicar esta nueva disciplina llamada diplomacia deportiva.

Palabras clave: Diplomacia Deportiva, Deporte, Diplomacia Pública, Sector Deportivo, Eventos Deportivos.

Abstract: Sport is the most important social phenomenon in recent years with unparalleled multinational scope. As such it can be used as an instrument of foreign policy by the countries and companies through the so-called sports diplomacy.

This article addresses this subject from the point of view of the objectives that sport can contribute to reach and the means that can be used.

The objectives are very varied, structured in objectives of identification, exchange and contribution. Regarding the means, these include sports agents, activities, infrastructures, knowledge and products and services.

The proper definition and management of these objectives and means represents great potential in the effort to structure, develop and, above all, apply this new discipline called sports diplomacy.

Key Words: Sports Diplomacy, Sport, Public Diplomacy, Sport Sector, Sport Events.

Recepción original:21-4-2020

Aceptación original: 6-7-2020

\section{INTRODUCCIÓN.}

El presente artículo pretende, en primer lugar, destacar la relevancia que esta disciplina está adquiriendo, aunque de una manera desestructurada y sin ser consciente de la relevancia y potencialidad. A continuación, se analizan los diferentes objetivos que, a través de su utilización, se pueden llegar a conseguir, para posteriormente proponer los diversos medios a utilizar para su ejecución. 
Finalmente, como conclusión, se propone desarrollar esta disciplina a futuro, tanto desde el punto de vista de su definición, como de implantación práctica a la vez que se destacan los riesgos que su sobreutilización puede producir.

\section{LA IMPORTANCIA DE LA DIPLOMACIA DEPORTIVA.}

El deporte ha adquirido una dimensión sin parangón en los últimos años y es claramente un fenómeno social que se ha desarrollado con gran intensidad durante el siglo XX y que, en el siglo actual, se ha consolidado como uno de los elementos de mayor interés y repercusión multinacional.

Los grandes eventos deportivos, los deportistas que participan en ellos y las entidades que los aglutinan a unos y a otros son internacionalmente conocidos y, en la mayoría de los casos, respetados y admirados.

Desde el punto de vista económico, el deporte es un sector que representa el 3,5\% del PIB de la Unión Europea y que ocupa el 5\% de la población activa ${ }^{1}$, lo cual muestra claramente la relevancia del mismo también en lo que respecta a la creación de riqueza.

Sin embargo, lo más relevante del deporte a los efectos de este análisis, es que tiene otra serie de connotaciones que lo convierten en una disciplina única muy propensa para impulsar las relaciones internacionales:

- El deporte es un elemento aglutinador a nivel interno en los países, que permite superar diferencias políticas, geográficas, culturales, etc., y fomenta el sentimiento de pertenencia y de identificación con el colectivo y con la identidad país.

- El deporte es un entorno amigable y relajado en el que, si bien existe competencia entre los países, como en muchos otros ámbitos, el respeto por las reglas de juego y por el rival es fundamental. El ambiente relajado de las competiciones, la fiesta alrededor de las mismas, su carácter lúdico, etc., ayudan a generar una atmósfera adecuada.

Se trata de entornos de competencia sana, con reglas establecidas, "batallas pacíficas" (como decía la cantante Shakira en

1 PricewaterhouseCoopers (PWC), "Changing the Game report", Diciembre de 2011. https://www.pwc.com/gr/en/publications/assets/global-sports-outlook-2011.pdf [fecha de consulta: 14/04/2020] 
la canción oficial de la Copa del Mundo de Fútbol de Sudáfrica 2010 "la única justa de las batallas"). Además, las reglas las aplica un tercero que a todas luces se supone (y lo es en la gran mayoría de los casos) neutral. Son formas amistosas de competencia e incluso de elaboración de rankings entre países que generan una rivalidad sana.

- El deporte en general y algunos deportes en particular son un foco de atención y de entretenimiento muy valorados. Los niveles de aceptación multinacional de algunos deportes los convierten en herramientas muy poderosas para quien los pueda gestionar. Las audiencias de los grandes eventos deportivos demuestran dichos niveles de aceptación, como por ejemplo los 26.000 millones de audiencia acumulada en la Copa del Mundo de la FIFA en Sudáfrica, superadas en la edición celebrada en Brasil y en Rusia, o los 4.000 millones de la ceremonia de apertura de Londres 2012.

- En un mundo interconectado como el actual, en el que las nuevas tecnologías hacen fluir la información de forma muy rápida, el contenido deportivo es uno de los más apreciados, transmitidos y seguidos.

- Los eventos internacionales fomentan de manera propicia el contacto entre diferentes países, culturas, religiones, etc., lo que genera relaciones independientemente del origen de cada uno de los participantes.

En estas competiciones los atletas se convierten en iconos internacionales, más allá de la nacionalidad de cada uno. Además, los eventos son una ocasión inigualable para mostrar y conocer otras culturas, personas y lugares de los que disfrutar.

- El deporte y los eventos deportivos son un elemento de estandarización internacional sin parangón, de tal forma que se genera un lenguaje y una dinámica comunes en su funcionamiento y desarrollo que es aceptada por todos, lo que constituye un espacio común de convivencia muy inmediato. El deporte y las competiciones son iguales en todas partes por lo que no hay que explicar nada a los agentes involucrados. Ello contribuye a la superación de diferentes tipos de barreras internacionales:

- Barreras idiomáticas; se puede incluso decir que son una forma de comunicación en sí misma; personas que no hablan 
un idioma común, pueden entenderse perfectamente practicando o compitiendo en un deporte.

- Supera las fronteras de los países, consiguiendo que deportistas, entidades y aficionados se identifiquen con ciertos lugares, independientemente de su nacionalidad o del grado de vinculación real que tengan con los mismos. El deporte no tiene fronteras, transciende las fronteras políticas, lo cual, paradójicamente lo hace una herramienta muy relevante para los estados que sepan utilizarlo.

- Supera las barreras económicas entre países ya que, si bien normalmente los resultados deportivos van asociados al grado de desarrollo de cada país, existen deportes y disciplinas en las que esto no tiene por qué ser así y países con menores recursos pueden obtener resultados punteros.

- Ayuda a reducir las tensiones o diferencias que puedan existir en las relaciones entre los países y los iguala por encima de diversos factores como los sociales, poblacionales, etc.

- En el mundo del deporte existen multitud de agentes involucrados y de lo más diversos, desde personas individuales (deportistas) con un efecto insospechado, hasta eventos, pasando por entidades públicas y privadas de muy distintos tipos. Surgen por tanto un gran número de oportunidades de colaboración y de acción de diplomacia pública por muy diferentes intervinientes.

- El deporte está muy presente y de manera muy extendida en las redes sociales, lo que puede convertirlo en un instrumento muy efectivo de lo que Anne-Marie Slaughter llama "collaborative power" ${ }^{2}$, o poder colaborativo, es decir, cómo el poder de muchos puede conseguir más de lo que cada uno puede hacer por sí solo. Los aficionados de un club, los seguidores de un deportista, los asistentes a un evento, etc., pueden constituirse en grupos de presión "espontáneos" con gran capacidad de influencia.

- Los eventos de práctica deportiva (no profesionales) se convierten en retos comunes a superar en los que se producen mul-

2 SLAUGHTER, A. M., "A New Theory for the Foreign Policy Frontier: Collaborative Power", en The power of many can accomplish more than any one can do alone -and that distinction is different than the traditional classification of hard and soft power.

http://www.theatlantic.com/international/archive/2011/11/a-new-theory-for-theforeign-policy-frontier-collaborative-power/249260/ [fecha de consulta: 10/04/2020] 
titud de relaciones, conocimiento de lugares y contacto entre personas de muy diferentes países.

Por estos factores es razonable concluir que el deporte y todo lo que le rodea se puede convertir en un instrumento de relación internacional muy relevante. Esta potencialmente poderosa contribución del deporte es lo que he definido en mi libro homónimo como diplomacia deportiva ${ }^{3}$, es decir, la utilización del deporte como instrumento de diplomacia pública para su contribución a determinados objetivos de una forma estructurada y más allá de los posibles resultados deportivos.

Y aquí está precisamente la base del desarrollo como disciplina y lo que es más importante, como instrumento útil de la diplomacia deportiva; definir los objetivos a los que puede y debe contribuir e incluirla dentro de una estrategia bien definida, articulada e implantada de acción exterior.

Como detallaré posteriormente, la diplomacia deportiva puede llevarse a cabo por muy diversos agentes, por lo que encaja dentro del concepto de "diplomacia privada", según el análisis de Luis Melgar, que contempla "la participación de actores no estatales en las relaciones internacionales, tales como empresas multinacionales, medios de comunicación, universidades, think tanks o incluso la propia opinión pública"4.

En la gran mayoría de los países, hasta el momento, las actividades mal llamadas de diplomacia deportiva se han basado primordialmente en la explotación y comunicación de forma muy poco estructurada de los resultados deportivos más o menos exitosos de las entidades y deportistas nacionales.

Es sintomático por ejemplo el caso de España, donde las selecciones nacionales de deportes de equipo, los tenistas, los pilotos (tanto de coches, como de motos), los regatistas, etc., le han otorgado un posicionamiento inigualable por lo continuado de sus éxitos y, sobre todo, por la forma de conseguirlos, mediante la asociación de los valores fundamentales del deporte, de esfuerzo limpio y respeto por el rival. Sin embargo, todas estas actividades y logros no se han estructurado en una acción común que permitiera maximizar su retorno en términos de objetivos diplomáticos.

3 SOBRINO, J., Diplomacia Deportiva, Andavira Editorial, Santiago de Compostela, 2014.

4 MELGAR, L., "Diplomacia Público Privada", Comillas Journal of International Relations, $\mathrm{n}^{\circ} 1,2014$, págs. 4-15. 
La diplomacia deportiva se ha basado también en la acción internacional aislada de determinadas entidades que, por su prestigio, número de seguidores, éxitos deportivos, relevancia de sus deportistas o por todos estos factores a la vez, han tenido una importante proyección internacional $\mathrm{y}$, a la vez que desarrollan sus propias actividades, difunden el nombre de España allá por donde van. Casos como el de los principales clubes de fútbol o las federaciones de determinados deportes con gran seguimiento son paradigmáticos en este sentido.

Sin embargo, como se ha explicado en otras ocasiones ${ }^{5}$ y en diferentes foros, el deporte es un sector económico que no sólo se basa en los éxitos competitivos, que nunca están garantizados, a pesar de la mejor preparación y el mayor esfuerzo, sino en la estructuración y potenciación adecuada de todas las actividades económicas relacionadas con el mismo, que son muchas y variadas. Esta apreciación permite situar a la diplomacia deportiva también en el ámbito de la "diplomacia económica", como "objetivo autónomo prioritario de toda política exterior"6.

El deporte es una realidad pluridisciplinar, con múltiples implicaciones y una gran variedad de agentes involucrados. Por tanto, el deporte, en sus múltiples acepciones, puede ser un elemento fundamental de contribución a la acción internacional de un país, incluso de una forma más intensa y, sobre todo, efectiva, que otros tipos de acciones que se puedan poner en marcha.

Sin embargo, el deporte no debe ser sólo un "facilitador de relaciones" o un proyector de imágenes. Se debe ampliar el concepto, hasta situarlo en la utilización del deporte para la contribución a los objetivos de cada país o cada geografía, cualesquiera que éstos sean. Siempre que exista una estrategia definida a nivel de la acción internacional de un país, el deporte podrá ser empleado de múltiples maneras para contribuir a la misma. Por ello, la premisa fundamental para que se puede desarrollar la diplomacia deportiva en toda su expresión, es que la geografía que quiera aprovecharla debe haber definido previamente cuáles son sus objetivos estratégicos y así establecer a posteriori cómo el deporte, en el más amplio sentido de la palabra, puede contribuir a la consecución de los mismos. Precisamente por ello, se abordará posteriormente en este trabajo, cuáles

5 VARIOS AUTORES, Retos de nuestra acción exterior: Diplomacia Pública y Marca España, Colección Escuela Diplomática. Madrid, 2012.

6 MORILLAS GÓMEZ, J., "La diplomacia económica", Boletín económico del ICE, Información Comercial Española, nº 2664, 2000, págs. 41-44. 
son esos objetivos que se pretenden conseguir, así como los medios para lograrlos.

Una adecuada estrategia de diplomacia deportiva supone la contribución tanto de entidades públicas como privadas en pos de unos objetivos concretos comunes, aprovechando además los beneficios que aporta la digitalización. Como señalan diversos autores el objetivo debe ser "la influencia en la opinión pública que se ejecuta mediante la información y la comunicación"7, siendo una de las actividades principales el deporte.

El deporte por sí mismo no hace milagros (normalmente), más allá de que sus efectos tengan una gran repercusión pública y mediática. Una ciudad que se presente a un proceso de candidatura para unos Juegos Olímpicos o un país que quiera organizar un campeonato del mundo, por citar sólo dos ejemplos, debe tener muy claro para qué quiere llevarlos a cabo y, sobre todo, a qué objetivos dentro de su estrategia corporativa van a contribuir y cómo.

Lo demás supondrá malgastar dinero contribuyendo en la mayoría de los casos simplemente a satisfacer anhelos personales. El propio Sebastian Coe (Embajador para el legado olímpico y paralímpico de Londres 2012) en una intervención pública en Madrid en marzo de 2013, apuntó con gran criterio que "la pregunta importante a la hora de abordar una candidatura para albergar los JJOO no es el "cómo", sino el "por qué" se quiere organizar los Juegos ${ }^{8}$.

Siempre he defendido que la planificación estratégica es fundamental a la hora de plantearse cualquier acción en el mundo del deporte. La estrategia es la función empresarial que permite establecer una visión a largo plazo y ponerla en práctica ${ }^{9}$. El aprovechamiento del deporte para contribuir a la acción diplomática debe ser una estrategia muy a largo plazo y con múltiples vertientes. Entre otros muchos factores, es necesario compatibilizar el posicionamiento a nivel país con los posibles posicionamientos regionales o locales (de ciudades con suficiente proyección internacional).

Es una estrategia desde la perspectiva de país/región y, por tanto, puede ser aplicada, con sus correspondientes adaptaciones y varia-

\footnotetext{
7 MANFREDi, J. L., PENA, A., LA PORTE, M. T., PERUJO, F., BALLERA, J., "Comunicación y desarrollo en la era digital". Congreso AE-IC, 2010, pág. 19.

8 Foro Europa Press, Madrid, 7 de marzo de 2013: https://www.europapress.es/ madrid/noticia-jjsebastian-coe-inaugura-martes-vi-temporada-desayunos-deportivos-europa-press-20130304093459.html [fecha de consulta: 01/04/2020]

9 JOHNSON, G., WHITTINGTON, R. SCHOLES, K., ANGWIN, D. REGNÉR, P., Exploring Strategy. Text and Cases. Tenth edition. Pearson. Reino Unido. 2014.
} 
ciones, según los lugares. La diplomacia deportiva puede integrarse dentro del concepto amplio de "paradiplomacia", en el sentido que lo utiliza Zidane Zeraoui, como "concepto paraguas, que incluya todas las demás acepciones que representan casos específicos de política internacional de regiones" 10 .

Es importante abordar la cuestión de quién es el "sujeto de la diplomacia deportiva", ya que dicha acción no se limita ya en ningún caso al estado, sino que administraciones públicas de menor ámbito geográfico se suman a la misma.

Juan Luis Manfredi ${ }^{11}$ pone de manifiesto que "en el ámbito político territorial, el final del monopolio estatal se asienta en la literatura académica con ocasión del final de la guerra fría. La denominada "paradiplomacia" aparece como el ejercicio directo y en diverso grado, por parte de los Estados federados, de actividades en el extranjero. Tal crecimiento tiene su antecedente en el ámbito municipal que es capaz de influir en el desarrollo de la actividad internacional. Según Salomón, "las ciudades son un actor internacional cada vez más consistente y organizado. Las autoridades locales, por su parte, asumen cada vez mayores responsabilidades en el liderazgo del proceso de internacionalización". Un buen ejemplo del entonces creciente interés fue el proyecto NICE (New International Cities Era) que analizó la paradiplomacia urbana y el advenimiento de las ciudades internacionales".

Si, además, ampliamos el concepto, veremos cómo los agentes involucrados en dicha actividad, aumentan de manera significativa, incluso llegando a la sociedad en general a través de los aficionados al deporte o los practicantes del mismo. Incluso se puede hablar de un componente de la "celebrity diplomacy"12 (diplomacia de celebridades), cuando estudiemos la acción de los deportistas.

Así, para poder aplicar la diplomacia deportiva en todo su potencial, es fundamental determinar cuáles son los objetivos potenciales que, a través de ella, se pueden llegar a conseguir.

10 ZERAOUI, Z., "Para entender la paradiplomacia", Desafíos, semestre I de 2016 págs. $15-34$.

11 MANFREDI, J.L. "Hacia una teoría comunicativa de la diplomacia pública". Comunicación y sociedad, Volumen XXIV. 2, 2011, págs. 199-225.

12 COOPER, A., Celebrity Diplomacy, Paradigm Publishers, Nueva York, 2008. 


\section{LOS OBJETIVOS DE LA DIPLOMACIA DEPORTIVA.}

La diplomacia por la diplomacia, por tanto, no tiene ningún sentido, más allá de las relaciones próximas y cordiales que los países deben tener entre ellos; lo que debe existir desde el punto de vista de la diplomacia deportiva es una clara asociación a una serie de objetivos o cometidos por los que cobre sentido y que le otorguen una dirección clara y, sobre todo, elementos de contraste y comprobación de su eficacia.

Esta estrategia de diplomacia deportiva estructurada y no basada exclusivamente en los resultados de los deportistas puede contribuir a muy diferentes tipos de objetivos. Se ha hablado recientemente de diferentes ámbitos de la diplomacia, como, por ejemplo, la diplomacia del "emprendimento empresarial"13 o la "diplomacia digital"14, que permiten crear nuevos tipos de estrategias, aprovechando las oportunidades que representan. La diplomacia en general y, desde luego, la deportiva en particular, no es un fin en sí misma, sino que, por el contrario, se trata de un medio para la consecución de unos objetivos. Y ahí es donde está la clave, los países deben tener clara cuál es su estrategia internacional en diferentes ámbitos y, en función de la misma, utilizar al sector deportivo y a sus agentes en consecuencia.

Debe existir una constante coordinación entre los responsables de la acción internacional de un país y los agentes deportivos, entendiendo por tales todas las personas físicas y jurídicas que realizan su actividad en el sector deportivo.

Asimismo, debe ser un instrumento novedoso, valioso y, sobre todo, estructurado para la acción internacional de las diferentes entidades y, por tanto, debe estar al servicio de la misma.

La entidad encargada de las actividades deportivas deberá tomar como "input" las prioridades internacionales tanto desde el punto de vista de objetivos del órgano al que sirve, como de geografías prioritarias.

Bien es verdad que el deporte incorpora aspectos particulares que deberán ser tenidos en cuenta, tales como los eventos internacionales, los resultados deportivos, los deportes más populares en

13 SÄFTESCU, R. G., "Oportunidades para un nuevo componente de la diplomacia: diplomacia basada en el emprendimiento empresarial". Revista de Estudios Políticos y Estratégicos, Vol. 7, n¹, 2019, págs. 42-58.

14 MANFREDI, J. L., "El desafío de la diplomacia digital". Análisis del Real Instituto Elcano (ARI), n ${ }^{\circ}$ 15, 2014. 
determinadas localizaciones, etc., pero en todo caso, el deporte se debe poner al servicio de la acción exterior.

La acción diplomática a través del deporte tiene dos vertientes fundamentales, la interna (relacionada con la autoimagen y las capacidades propias) y la externa (relacionada con la proyección y las relaciones y vínculos internacionales).

A través de las acciones relacionadas con el deporte se pueden conseguir múltiples tipos de objetivos, que precisamente suponen una evolución desde los elementos más identitarios, de posicionamiento y, por tanto, internos, hasta los de carácter más externo o de relación con otros países, sean éstos de intercambio económico o más altruistas de contribución al desarrollo.

El siguiente esquema refleja los diferentes tipos de objetivos a los que puede contribuir la diplomacia deportiva:

Objetivos de la diplomacia deportiva

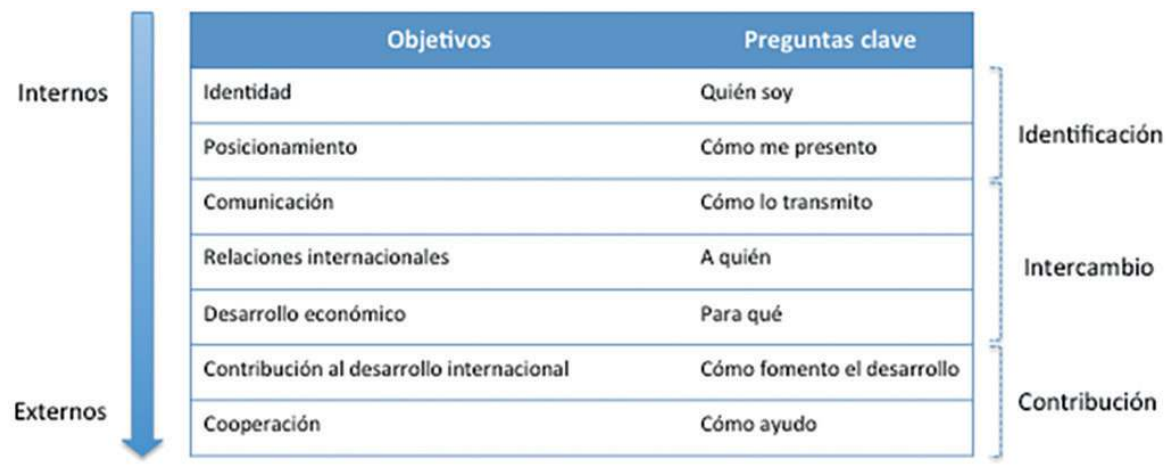

Fuente: Elaboración propia.

A continuación, se detallan cada uno de estos objetivos a los que puede contribuir la diplomacia deportiva, evolucionando de los más internos a lo más externos:

A) Objetivos de identificación:

1. Fomento del sentimiento identitario propio: los acontecimientos deportivos, la participación de los países en los mismos o, incluso, la organización de éstos, produce con gran naturalidad y efectos inmediatos un sentimiento de pertenencia a un 
colectivo. El propio Nelson Mandela lo entendió muy bien al aprovechar la organización de la Copa Mundial de rugby de 1995 para unir a su país por encima de los conflictos raciales, en un momento de gran dificultad, en torno a un objetivo común y utilizando un deporte tradicionalmente asociado a los blancos. Sudáfrica ganó 15-12 en la final a Nueva Zelanda y la hazaña fue recogida posteriormente en la novela "El factor humano" de John Carlin, que, a su vez, inspiró la película "Invictus" de Clint Eastwood. Como refleja J. Simon Rofe ${ }^{15}$, la diplomacia deportiva también puede ser un instrumento de gran dimensión para la pacificación de determinados lugares después de conflictos armados.

Por otra parte, la presencia de deportistas punteros de un determinado país, también sirve como forma de exaltación nacional, de los sentimientos de pertenencia y de los vínculos entre las personas de una misma sociedad. Deportistas históricos como Airton Senna, Maradona o Yao Ming son sólo tres ejemplos de esta circunstancia.

Otro aspecto relevante que puede potenciar el desarrollo de dicho sentimiento de pertenencia es la promoción y gestión del voluntariado en los eventos deportivos. La participación altruista de muchos ciudadanos y su vocación de servicio suponen un elemento muy importante de generación de comunidad y de sentimiento colectivo.

Además, puede contribuir también a la transmisión de una determinada imagen ante personas de otros países, como por ejemplo fue el caso de los voluntarios en los Juegos Olímpicos de Londres y su extraordinaria labor de atención a los asistentes.

También el deporte es un instrumento muy poderoso para la integración social, incluso de personas de diversas nacionalidades que conviven en una misma localización, como manera de generar espacios de convivencia y actividades comunes.

Puede ser un instrumento, a través de la organización de grandes acontecimientos deportivos, para "apoyar estructuras de estado en países en desarrollo", ya que puede contribuir a

15 ROFE, S., Sport and Diplomacy. Games within games. Manchester University Press, Manchester, 2018. 
afianzar departamentos gubernamentales involucrados en la ejecución de dichos eventos. ${ }^{16}$

2. Posicionamiento internacional: la actividad diplomática pública está muy vinculada con el posicionamiento que cada país, región o ciudad quiera fomentar; desarrollar capacidades relacionadas con el deporte en sentido amplio puede suponer una identificación muy interesante a transmitir frente a terceros y en foros internacionales. El deporte adquiere un protagonismo que va mucho más allá de su "territorio originario"17.

Es sintomático por ejemplo el caso de Australia y su utilización del fútbol en la Copa de Asia de 2015 para tratar de mejorar sus relaciones e integración con el continente asiático; como la propia Federación Australiana destacaba "El fútbol se convertirá en mucho más que un deporte. Tendrá un rol cada vez más importante en la cohesión social, integración de la comunidad, salud física y bienestar y relaciones internacionales y desarrollo económico, particularmente en Asia"18.

Por su parte, diversos países, como Dinamarca, Holanda, Reino Unido, entre otros, han creado en los últimos años oficinas dedicadas a atraer eventos deportivos internacionales, aprovechando un posicionamiento (real o deseado) de idoneidad para la organización de eventos.

Dicho posicionamiento se identifica con el concepto de "place branding" o "marca lugar"19: La organización de eventos deportivos, la existencia de entidades deportivas de referencia, la disponibilidad de infraestructuras deportivas o de espacios naturales, o la existencia de un clima determinado, son elementos que deben aprovecharse a nivel internacional para posicionarse como referencia en el sector.

Además de los eventos que un determinado país pueda organizar y del grado de práctica deportiva y de actividad económica asociada al mismo, el hecho de que representantes de

16 DOWSE, S., "Power Play: International Politics, Germany, South Africa and the FIFA World Cup", SAIIA Occasional Paper, No. 82, South African Institute of International Affairs Sudáfrica, 2011.

17 FERNÁNDEZ PEÑA, E., "Deporte para la diplomacia pública: hacia una visión compleja”, Análisis del Real Instituto Elcano, nº 60, 2019.

18 ROFE, S., 2018, o. c.

19 MUÑIZ MARTÍNEZ, N., CERVANTES BLANCO, M., "Marketing de ciudades y "Place Branding"”, Pecunia: revista de la Facultad de Ciencias Económicas y Empresariales, $n^{\circ}$. Extra 1, 2010, págs. 123-149. 
los países estén constantemente compitiendo a nivel internacional en los diferentes deportes supone en sí mismo un elemento diferenciador y, por supuesto, de proyección de la marca país como pocos.

Que un país como España, por ejemplo, haya ganado en los últimos años los campeonatos mundiales de los deportes de equipo más relevantes a nivel internacional ha sido claramente un elemento de desarrollo de su marca país muy poderoso, el cual se debe aprovechar, si bien no como el elemento más importante de la diplomacia deportiva, pero sí como un contribuidor muy relevante.

Incluso los propios procesos de candidatura para la organización de eventos deportivos de nivel mundial, tienen un importante impacto sobre la imagen de las ciudades o países. Estos procesos suponen la oportunidad para los candidatos de presentar las bondades y los activos de su país y, lo que es todavía más relevante, son procesos en los que los países se comparan con otros candidatos según criterios más o menos objetivos. Por ello, bien aprovechado y gestionado, un proceso de candidatura puede destacar determinadas fortalezas y aspectos diferenciales frente a terceros, lo que supone una importante posibilidad de posicionamiento y diferenciación.

En estos procesos, jefes de estado, primeros ministros, ministros, autoridades regionales y locales, además de otros muchos colectivos de la sociedad civil, se ponen a disposición de los evaluadores de los organismos internacionales, incluso respondiendo preguntas muy específicas, lo que supone una doble oportunidad, tanto de realizar un ejercicio de revisión para mejorar los servicios, como de proyección de imagen objetiva y con gran capacidad de impacto.

B) Objetivos de intercambio:

1. Comunicación internacional: El deporte es un instrumento sin parangón a la hora de realizar campañas de comunicación y promoción internacionales por un coste infinitamente menor al que supondrían campañas equivalentes contratadas en medios internacionales. "La acción internacional en nuestros días ya no sólo consiste en gestionar la política exterior de un país, sino también en enviar los mensajes adecuados a públicos 
objetivo" ${ }^{20}$, cuestión que el deporte puede realizar de una forma muy natural.

Incluso la simple candidatura a albergar un gran evento internacional de primer nivel supone un impacto comunicativo muy relevante. Por otra parte, la propia organización de un evento otorga una oportunidad de comunicación muy importante, no sólo durante la celebración del mismo, sino durante las fases previas o de clasificación en las que el nombre de la sede se repite de manera constante y sistemática, con el impacto que ello tiene en los diferentes lugares donde dichos eventos se celebran. Por ejemplo, el concepto "Road to..." acuñado por la UEFA para referirse al lugar donde se va a celebrar cada año la final de la Liga de Campeones (UEFA Champions League), supone que dicha ciudad se está proyectando durante todo un año por todos los lugares de Europa y del resto del mundo donde esta competición es seguida, hasta culminar con la celebración de la final, con el impacto que la misma supone, incluidos los factores económicos.

Planificar y desarrollar la estrategia de comunicación de un evento desde el momento en el que se le concede el derecho de organización a la entidad correspondiente, es un instrumento único de comunicación, sobre todo por la naturalidad con la que dicha estrategia se propaga y por el interés paulatinamente creciente que el lugar o lugares donde el evento se va a celebrar van despertando en los aficionados en general que quieren acudir al mismo y, sobre todo, y lo que es todavía más importante, en los medios de comunicación.

Por otra parte, los procesos de candidatura a los que se hacía mención anteriormente también suponen una oportunidad de comunicación de gran impacto y muy económica si la comparamos con una campaña de alcance equivalente que el país o la ciudad candidatos tuvieran que afrontar contratando los espacios de la misma.

Dentro de esas actividades de comunicación un elemento fundamental es el fomento internacional que se puede producir sobre el idioma del país. El atractivo que supone el deporte y, sobre todo, la actividad y los resultados de determinados deportistas, tiene un efecto multiplicador de seguimiento de los

20 RODRÍGUEZ GÓMEZ, A. A., "La comunicación como instrumento de la diplomacia pública", Estudios sobre el mensaje periodístico. $\mathrm{N}^{\circ}$ Extra 19, 2 (Abril), 2013, págs. 953-961. 
mismos, que acaba teniendo un impacto sobre el lenguaje de las comunicaciones realizadas, con las consiguientes implicaciones económicas que ello conlleva ${ }^{21}$.

Desde el punto de vista de la comunicación es necesario destacar que, por muchos y muy desarrollados activos que un determinado país tenga y, por muy bien que defina su posicionamiento, si no se realiza una adecuada comunicación del mismo, dicho posicionamiento no será efectivo.

Es muy importante verificar y controlar las percepciones de la marca país en diferentes entornos. Para ello, el deporte se puede convertir en una herramienta muy eficaz por los múltiples prismas y perspectivas que aporta. Los valores del deporte son muy variados $\mathrm{y}$, por ello, pueden apoyar diferentes estrategias de comunicación. No quiere esto decir que el posicionamiento y, por tanto, la transmisión del mismo, tengan que variar sustancialmente (eso eliminaría el propio posicionamiento), pero sí que puede servir para destacar unos determinados aspectos u otros en función de las prioridades estratégicas y del público objetivo.

Los valores del deporte son muy diversos: Trabajo en equipo, superación personal, respeto por el rival y por las reglas, etc. Sin embargo, hay valores que se pueden asociar más al deporte profesional (éxito, desarrollo económico, experiencia y capacidad técnica, etc.) y otros a la práctica deportiva (salud, integración, solidaridad, etc.). Sea como fuere, las posibilidades y opciones de comunicación son muy amplias y, como tales, hay que aprovecharlas.

En función de los objetivos y de las zonas geográficas prioritarias, tendrá más sentido utilizar unos medios u otros y unos mensajes u otros.

2. Gestión de las relaciones entre países: El establecimiento, mantenimiento o mejora de las relaciones entre países a través de la acción del deporte debe ser uno de los principales objetivos de la diplomacia deportiva, ya sea en un ámbito bilateral o multilateral. Tal y como señala Manfredi, "la diplomacia tiene cuatro objetivos principales (representar, negociar, proteger y

21 GARCÍA DELGADO, L. (coord.), ALONSO LERA, J. A., (coord..), JIMÉNEZ, J. C. (coord..), BOMBARELLI, M. E., (coord.), El español, lengua global, Santillana, Instituto Cervantes, España, 2010. 
promover los intereses de un Estado ante terceros)"22. En este caso el deporte puede ser un contribuidor clave en todos ellos.

Los vínculos comunes que puedan existir entre diferentes países son tan importantes que ciertas competiciones deportivas internacionales son creadas al amparo de los mismos. En la mayoría de los casos dichos vínculos son geográficos (como son los campeonatos continentales de múltiples deportes o los juegos continentales), aunque también pueden existir otros de tipo cultural (Juegos del Mediterráneo) o, incluso, histórico-coloniales, como es el caso de los Juegos de la Commonwealth, entre los que caben destacar los casos de Manchester 2002 y Glasgow $2014^{23}$.

En ocasiones el deporte se convierte en uno de los escasos instrumentos que hacen posible la relación y el contacto entre países o, cuanto menos, un factor determinante para que se retomen relaciones que en un momento dado podían ser inexistentes, por no decir hostiles, como por ejemplo la "diplomacia del cricket" entre La India y Pakistán, la presencia de jugadores cubanos y venezolanos de béisbol en la liga profesional de Estados Unidos, la visita de jugadores de la NBA a Corea del Norte, o el caso más antiguo del tenis de mesa y las relaciones entre Estados Unidos y China, en los años 70 del pasado siglo.

En otras ocasiones, sin embargo, el deporte puede ser una fuente de conflicto entre países, que es necesario gestionar y minimizar adecuadamente. Casos como el de la bandera de Corea del Sur en el video marcador de Londres 2012 en un partido de fútbol, mientras se anunciaban los nombres de las jugadoras de Corea del Norte o el caso de la bandera de la marina italiana en el morro de los Ferrari en el Gran Premio de la India de 2012, meses después de un conflicto entre ambos países, son sólo ejemplos concretos de situaciones que el deporte puede provocar y que, por tanto, es necesario abordar con sumo cuidado.

3. Contribución económica: Con un mundo cada vez más interconectado e interdependiente, aquellas zonas que logren un

22 MANFREDI, J. L., "El desafío de la diplomacia digital”. Análisis del Real Instituto Elcano (ARI), no 15, 2014.

23 En el caso de Manchester además supuso una oportunidad para rejuvenecer la ciudad y la región frente a problemas socio-económicos y en el de Glasgow se aprovechó para el desarrollo estratégico de la región. ROFE, S., 1018, o. c. 
posicionamiento de éxito en la industria deportiva y en el deporte pueden apalancarse en dichas capacidades como elementos críticos de la acción diplomática. Como señala García Rebollar, se están consolidando "redes exteriores especializadas" que son instrumentos muy valiosos de diplomacia económica ${ }^{24}$.

Disponer de eventos muy apreciados, entidades deportivas reconocidas internacionalmente, deportistas y técnicos muy demandados o empresas punteras del sector, puede constituir un elemento muy poderoso de negociación internacional, en línea con dichas redes especializadas.

Estos componentes de la industria deportiva de un país pueden incluirse dentro de acuerdos de colaboración internacionales, como forma de contraprestación por aportaciones realizadas en otros ámbitos de relación, o pueden generar retornos económicos directos a través de transacciones en el sector.

Ya sea a nivel público, como elemento de negociación, o por el desarrollo de negocio de entidades privadas, la actividad deportiva puede generar rendimientos económicos relevantes, como, por ejemplo:

a) Organización de eventos deportivos internacionales con retornos directos (beneficio del propio evento) e indirectos por el impacto en otras entidades nacionales y sectores diversos. Es necesario decir que está pendiente de desarrollo una metodología ampliamente aceptada de determinación de los efectos concretos y detallados de los grandes eventos deportivos.

b) Promoción internacional de eventos nacionales, como fuente de generación de riqueza por la venta de derechos asociados a dichos eventos. Por ejemplo, las ligas europeas más relevantes de los principales deportes están llevando a cabo una labor de promoción y comercialización muy importante en nuevos mercados (fundamentalmente del sudeste asiático). La Premier League o la Liga española están caminando en esta dirección.

24 GARCÍA REBOLLAR, A., "Notas sobre diplomacia económica”, Boletín Económico de ICE, Información Comercial Española, n 3000, 2010, págs. 23-34. 
c) Turismo deportivo: la disponibilidad de entornos naturales propicios, instalaciones punteras y accesibles, clima adecuado para la práctica deportiva, etc., provoca que determinados practicantes deportivos, normalmente con alto poder adquisitivo, quieran acudir a un país. Deportes como el golf, esquí, deportes acuáticos, carreras de larga distancia, triatlón, etc., son focos de atracción para turistas que, además, si su experiencia es positiva, pueden convertirse en grandes prescriptores a futuro.

Los eventos deportivos de alta competición también suponen una oportunidad inigualable para atraer turismo y, por tanto, actividad económica. Pero no sólo los grandes eventos que puntualmente se puedan organizar, que también, sino que se deben explotar y aprovechar los eventos regulares que se organizan habitualmente, como son los campeonatos nacionales de determinados deportes mayoritarios.

Otro aspecto relevante en relación al turismo, más vinculado al posicionamiento que a la propia contribución económica, son las mayores o menores facilidades que un determinado lugar provea para que las personas que lo visitan por otros motivos (negocios, culturales, sociales, etc.) puedan practicar actividad deportiva con facilidad. Muchos viajeros practicantes habituales de deporte aprecian la posibilidad de que en cualquiera de sus estancias puedan realizar, de manera sencilla e inmediata, actividades deportivas. En este caso, en lugar de "turismo deportivo", debemos hablar de "deporte para turistas".

d) Actividad y centros de preparación deportiva de equipos nacionales u otras entidades deportivas: disponer de instalaciones adecuadas y un clima benigno, cuando en otras partes del mundo existen temperaturas extremas, es un gran activo de cara a fomentar la presencia de deportistas de élite en una determinada geografía.

La existencia de centros de alto rendimiento o de tecnificación especializados supone también un activo importante de cara a la consolidación de esta actividad. Ciertos países pueden convertirse por ejemplo en los lugares de referencia para la aclimatación de deportistas de otros continentes cuando acuden al propio para competir en diferentes eventos. 
e) Formación técnica de preparadores y/o deportistas en ciertos deportes: el desarrollo de programas estructurados y actividades de preparación técnica en deportes en los que el país destaque a nivel internacional son un reclamo muy importante y generadores de actividad económica.

f) Congresos deportivos: cada vez es más común y frecuente que federaciones internacionales y otros organismos y empresas deportivas, organicen encuentros, reuniones, convenciones, etc., en las que tanto el número de asistentes, como, en algunos casos, la repercusión del evento en sí, son de gran relevancia y, por tanto, de gran interés para el lugar de organización.

g) Desarrollo de empresas nacionales en otros países en actividades relacionadas con el sector deportivo en sus diferentes vertientes. El deporte es un sector de actividad muy importante que, por ejemplo, en la Unión Europea supone el 3,5\% del PIB. La estimación a nivel mundial es que el mercado deportivo crezca de forma agregada desde 2011 hasta 2015 un 3,7\% hasta llegar a los 145,3 billones de dólares en dicha fecha ${ }^{25}$. Además, el deporte como sector de actividad se debe estructurar según la división básica entre deporte profesional y práctica deportiva, ya que las variables económicas de funcionamiento y los agentes intervinientes son distintos.

El deporte profesional se basa en tres actores principa$\operatorname{les}^{26}$, como son los deportistas, las entidades y los eventos, que se retroalimentan entre sí formando un círculo virtuoso: los mejores deportistas son contratados por las mejores entidades que acuden a los eventos más prestigiosos que, a su vez atraen a los mejores deportistas. Por su parte, el de práctica deportiva es un sector equiparable a sectores como el de la distribución tradicional.

Tanto en uno como en el otro, las posibilidades de desarrollo económico son muy diversas y el deporte debe ser considerado como un sector prioritario de contribución a

25 PricewaterhouseCoopers (PWC), "Changing the Game report", Diciembre de 2011, https://www.pwc.com/gr/en/publications/assets/global-sports-outlook-2011.pdf [fecha de consulta: 02/03/2020].

${ }_{26}$ SOBRINO, J., El deporte, sector de actividad económica, UNE Editorial, Madrid, 2013. 
la balanza de pagos en los países que apuesten por un posicionamiento decidido en relación al mismo.

C) Objetivos de Contribución:

1. Contribución al desarrollo social de terceros países: El deporte es un instrumento sin parangón para el desarrollo humano, en sus diferentes ámbitos:

a) Desarrollo físico: la adecuada y controlada práctica deportiva contribuye a mejorar el desarrollo de las personas o el bienestar de las mismas en función de la fase vital en la que se encuentren, desde la niñez, hasta la vejez.

b) Aprendizaje nutricional: la práctica deportiva debe llevar aparejadas adecuadas prácticas nutricionales, que deben ser transmitidas y fomentadas por los formadores deportivos y por los médicos que atienden a deportistas y practicantes.

c) Transmisión y aplicación de valores asociados al deporte, tales como el trabajo en equipo, el respeto por las reglas, por el rival, por la persona que es diferente, el esfuerzo personal, etc.

d) Como elemento integrador de colectivos menos favorecidos, tanto desde un punto de vista económico, como social o de capacidades físicas.

e) Y, finalmente, también se puede contribuir a la mejora técnica de la práctica deportiva de otros países, ya sea a través de una estrategia de formación o colaboración estructurada o mediante la actividad de personas individuales que, con su labor profesional, mejoran la preparación y el rendimiento del deporte en otros países. Este es el caso por ejemplo de España y el nivel técnico que sus entrenadores han adquirido en múltiples deportes que acaban convirtiéndose en seleccionadores nacionales o entrenadores de entidades de primer nivel de dichos deportes en diferentes países (fútbol, fútbol sala, balonmano, hockey hierba, etc.).

2. Todos estos elementos implican que un determinado país puede contribuir al desarrollo de otras geografías mediante la aplica- 
ción de programas relacionados con los valores del deporte. Sin duda, estas acciones generan unos vínculos especiales y un desarrollo de las relaciones entre las personas que participan y, por extensión, entre los países.

Cooperación: Ante situaciones excepcionales de necesidad o catástrofes naturales se ha comprobado el efecto extremadamente positivo que tiene el fomento del deporte entre los niños y jóvenes, como forma de desvío de la atención de la difícil realidad que pueden estar viviendo hacia actividades constructivas que fomenten su desarrollo. "La acción humanitaria tiene por objeto proteger y salvar vidas, prevenir y aliviar el sufrimiento humano, atender las necesidades básicas e inmediatas de la población y promover sus derechos" 27 , a lo cual el deporte puede contribuir de una manera muy natural.

Las políticas estructuradas de fomento del deporte pueden ser en sí mismas actividades de cooperación internacional muy valoradas y apreciadas por diversos países.

Organismos internacionales y Organizaciones No Gubernamentales (ONGs) de primer nivel cuentan constantemente con la colaboración de deportistas de élite para el desarrollo de actividades de cooperación. También las entidades deportivas más prestigiosas, normalmente a través de fundaciones constituidas al efecto, llevan a cabo actividades de este tipo en zonas desfavorecidas.

La coordinación y estructuración de todas estas actividades puede convertirse en un instrumento de diplomacia deportiva muy relevante y con alto impacto, tanto desde el punto de vista del emisor, como, lo que es incluso más importante, desde el del receptor.

Como se puede apreciar, la diplomacia deportiva puede contribuir a la consecución de muy diferentes y relevantes objetivos, siempre y cuando se desarrolle de una manera estructurada y con los medios adecuados. Precisamente a continuación pasamos a detallar dichos medios.

27 LÓPEZ-DÓRIGA PÉREZ, J., "La Marca España y la cooperación internacional para el desarrollo". Retos de nuestra acción exterior: Diplomacia Pública y Marca España, Colección Escuela Diplomática, Madrid, 2012. 


\section{LOS MEDIOS DE LA DIPLOMACIA DEPORTIVA.}

Debido a la gran amplitud del deporte como fenómeno económico y social, los instrumentos relacionados con él que se pueden utilizar en beneficio de la diplomacia deportiva son muy diversos. Se deben sumar por ello a los medios tradicionales de la diplomacia, como forma de contribuir a acabar con el "monopolio público sobre las relaciones internacionales ${ }^{28}$.

Para abordar los medios de la diplomacia deportiva, es necesario hacer referencia a la división del sector entre el deporte profesional y la práctica deportiva ${ }^{29}$. Las acciones de diplomacia deportiva son mucho más impactantes y obvias desde el punto de vista de la primera, precisamente por el carácter público y de gran repercusión de sus componentes (deportistas, entidades y eventos), si bien no puede dejarse de lado la diplomacia relacionada con la práctica deportiva, sobre todo en lo relativo al fomento del deporte base, como forma de desarrollo de la sociedad en general y de ciertos colectivos en particular.

Teniendo en cuenta esta distinción, los principales medios para el desarrollo de la diplomacia deportiva, son los siguientes:

Instrumentos

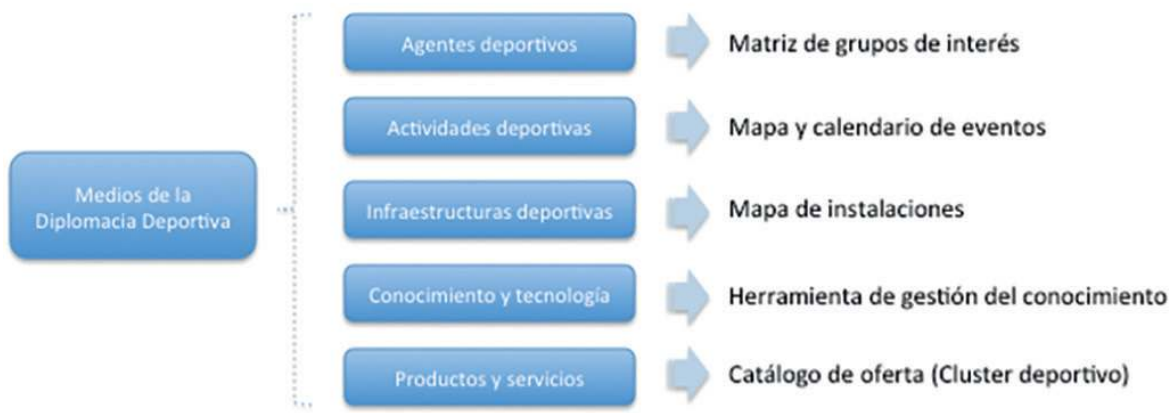

Fuente: Elaboración propia.

Algunos de estos medios son en sí mismos elementos constitutivos de un plan estratégico deportivo, el cual debe existir también como elemento fundamental a incorporar a la actividad exterior.

A. Los agentes deportivos: si bien la diplomacia deportiva debe ser la suma de las iniciativas y actividades de múltiples entidades en la que, además, la sociedad en su conjunto tiene una inter- 
vención muy importante, también es verdad que en tanto impacta a las relaciones entre países, debe existir un liderazgo, cuanto menos una coordinación, por una entidad pública que desarrolle el plan estratégico de utilización del deporte como actividad de estado (de región o de ciudad) que contribuya a la acción internacional.

Una de las principales peculiaridades de utilizar el deporte como instrumento de diplomacia pública es precisamente la gran diversidad de agentes que pueden intervenir en este proceso, además, con especial impacto por lo reconocibles y notorios que muchos de ellos son, tanto en ámbitos especializados, como para el público en general. Por ejemplo, los deportistas de élite se han convertido en auténticos iconos internacionales que traspasan las fronteras de su país de origen o del país en el que compiten, para ser reconocidos e identificados en cualquier lugar. Evidentemente, este nivel de exposición lleva acarreados también riesgos importantes en cuanto a la proyección de una imagen no adecuada o compatible con la que el país quiera transmitir. Resulta por tanto necesario identificar adecuadamente los agentes deportivos que pueden contribuir al desarrollo de la diplomacia deportiva.

B. Las actividades deportivas: desde el punto de las actividades deportivas, la distinción entre deporte profesional y práctica deportiva es muy relevante ya que los tipos de actividades que se pueden realizar en relación a una u otra son muy diferentes, desde la práctica individual privada de cualquier persona hasta los grandes acontecimientos deportivos internacionales.

C. Infraestructuras, instalaciones y localizaciones deportivas, o a las que se les pueda dar un uso deportivo: Se trata ante todo de realizar un inventario de las diferentes instalaciones y lugares que pueden contribuir al fomento de la práctica deportiva, no sólo para promover su uso por ciudadanos locales y extranjeros, sino también para posicionar internacionalmente las empresas que han realizado su construcción, son sus propietarias, llevan a cabo su gestión o realizan actividades en las mismas.

La existencia de dicho inventario es una herramienta esencial para conocer los activos de los que se dispone, pero también para identificar carencias que puedan ser cubiertas en función de las demandas que puedan surgir. Para ello, se deben acometer procesos de benchmarking internacional de los lu- 
gares con las infraestructuras más punteras y de modelos de gestión eficientes de las mismas.

Lo mismo debe ocurrir en el caso del posible aprovechamiento de espacios naturales para su adecuada utilización y garantizando en todo momento su conservación.

D. Gestión del conocimiento, mejores prácticas y desarrollo tecnológico: El deporte es un fenómeno en el que, al igual que en otros muchos sectores, la dedicación de recursos a la innovación y el desarrollo es esencial para la explotación de todo su potencial. Además, al tratarse de una disciplina tan amplia, existen grandes oportunidades de generación de conocimiento y, sobre todo, de aplicación práctica y masiva.

Por tanto, por pura política deportiva y como medio para la diplomacia deportiva, se deben fomentar procesos relacionados con la generación de conocimiento, su estructuración, su aplicación práctica y su transmisión a terceros.

Se trata de acciones relacionadas, tanto con la propia forma de gestionar y ejecutar la actividad deportiva (gestión de entidades y competiciones, tecnificación y rendimiento deportivo, emprendimiento y lanzamiento de nuevos productos, etc.), como con la mejora de la sociedad a través del deporte (salud y práctica deportiva, integración cultural, fomento de valores asociados a la actividad deportiva, etc.).

E. Desarrollo y comercialización de productos y servicios relacionados con el sector: tal y como hemos explicado en reiteradas ocasiones, los tipos de actividades económicas que se pueden desarrollar en relación al sector son muy variados. Desde empresas de fabricación y distribución de material deportivo, desarrollos tecnológicos, sistemas de información, diseño, medios de comunicación y redes sociales, hasta los sectores más relacionados con la organización y gestión de eventos deportivos, tales como construcción, transporte, logística, seguridad, turismo, etc.

La adecuada utilización de dichos medios supondrá la explotación en todo su potencial de la diplomacia deportiva. Sin embargo, también es necesario considerar las limitaciones o riesgos con los que el deporte, utilizado como instrumento diplomático, puede presentar. 


\section{RIESGOS DE LA DIPLOMACIA DEPORTIVA.}

Como hemos detallado a lo largo del presente trabajo, la diplomacia deportiva es una disciplina novedosa con un enorme potencial para su utilización para conseguir diferentes tipos de objetivos y a través de diversos medios. Sin embargo, no podemos dejar de apuntar los principales riesgos que la utilización del deporte como instrumento de relaciones internacionales puede suponer. Como apunta Rofe en las conclusiones de su trabajo sobre diplomacia deportiva $^{30}$, existen determinadas situaciones en las que se puede producir una mala utilización o uno efectos perniciosos del deporte en las relaciones internacionales.

Así, destaca sobre todo, factores como la posibilidad de utilización de los eventos deportivos como oportunidades de boicot contra países organizadores o participantes, aspecto este muy utilizado durante la guerra fría, la respuesta social de los ciudadanos contra la inversión en eventos deportivos que pueda limitar el gasto social (caso de Brasil durante la Copa del Mundo de 2014 y los Juegos Olímpicos de Río 2016), la contestación diplomática internacional ante problemas político-estratégicos en un país organizador (decisión de ciertos países a no enviar representantes institucionales a los Juegos Olímpicos de Sochi 2014 tras la invasión rusa de Crimea), la reducción paulatina y sistemática durante los últimos años de los países candidatos a organizar grandes eventos como Copas del Mundo o Juegos Olímpicos, el hecho de que los campeonatos deportivos se hayan convertido recientemente en objetivo prioritario de ataques terroristas (desde el atentado en la meta del maratón de Boston de abril de 2013), la ausencia de un auténtico legado e impacto positivo de los grandes eventos en las comunidades organizadoras (caso paradigmático entre otros muchos puede ser el de los Juegos de Atenas 2004) o, finalmente, las discutibles prácticas de gobernanza en instituciones deportivas nacionales e internacionales asociadas a prácticas de corrupción.

Al ser el deporte una actividad tan relevante desde un punto de vista social y mediático, el impacto de situaciones como las mencionadas provoca una mayor repercusión y, por tanto, constituyen una clara amenaza a la adecuada utilización de la diplomacia deportiva.

30 ROFE, S., 2018, o. $c$. 


\section{CONCLUSIÓN: EL MOMENTO PARA DESARROLLAR LA DIPLOMACIA DEPORTIVA.}

A pesar de las dificultades, los riesgos y la constante falta de estructuración, es el momento de desarrollar la diplomacia deportiva como una ciencia novedosa y prioritaria que puede suponer el cumplimiento de muy diversos objetivos. A ello deben contribuir las administraciones públicas y las entidades privadas, tanto deportivas, como de los múltiples sectores relacionados.

En el caso de las administraciones es necesario que participen, además de las entidades gestoras del deporte, la agencia de marca país (para los objetivos de identificación), la agencia de comercio exterior (para los objetivos de intercambio) y la agencia de cooperación (para los objetivos de contribución). De esta forma se dispone de una visión integral de todo lo que la diplomacia deportiva puede llegar a conseguir. El siguiente paso necesario debe ser la creación de un órgano específico que centralice toda esta actividad y, sobre todo, obtenga el máximo potencial de la misma. 
